\title{
Computed tomography in emergency department in patients with headache without focal neurological abnormalities
}

\author{
Tomislav Pavlovic ${ }^{1,2}$, Marina Milosevic ${ }^{3}$, Sanja Trtica', Franka Jelavic-Kojic ${ }^{1}$, \\ Hrvoje Budinčevic ${ }^{2,3}$, Dalibor Crvenkovic ${ }^{4}$ \\ ${ }^{1}$ Department of Radiology, "Sveti Duh" University Hospital, Zagreb, Croatia \\ ${ }^{2}$ University Josip Juraj Strossmayer in Osijek Faculty of Medicine, Croatia \\ ${ }^{3}$ Department of Neurology, "Sveti Duh" University Hospital, Zagreb, Croatia \\ ${ }^{4}$ Department of Surgery, "Sveti Duh" University Hospital, Zagreb, Croatia
}

\begin{abstract}
Introduction. Headache is a common reason for presentation in emergency department (ED). The aim of this research was to determine the incidence of positive computed tomography (CT) findings in patients with headache without focal neurological abnormalities in ED.

Material and methods. The results of the native CT scans in ED were retrospectively analyzed. Exclusion criteria included: focal neurological abnormalities, previous head trauma, underlying malignancy, brain metastasis, previous brain operation, dizziness, fever, nausea, vomiting, coagulopathy. As a clinically significant finding we took into account tumours, hemorrhage and acute ischemic lesion. 108 patients met these criteria. The age range was from 18 to 87 years, with mean of 49.5 years, $63 \%$ of the patients were female and $37 \%$ were male.

Results. Normal CT findings were found in 82 patients (75.9\%). 26 patients (24.1\%) had pathological findings, out of that number $17(15.7 \%)$ findings were clinically irrelevant and $9(8.3 \%)$ were clinically significant. Out of the 9 clinically significant findings, tumor process was found in $5(4.6 \%)$ patients, hemorrhage was found in $3(2.8 \%)$ patients and ischemic lesion was found in $1(0.9 \%)$ patient. In two patients with hemorrhage a subarachnoid hemorrhage was found, with an incidence of $1.8 \%$. All of the 9 clinically significant findings were further evaluated by MR and/or CT angiography and in 2 cases there was a change in initial CT diagnosis but without any change in the category of outcome.

Conclusions. Our research revealed $8.3 \%$ of clinically significant emergency examinations in patients with headache without focal neurological abnormnalities.
\end{abstract}

Keywords: headache, emergency department, computed tomography (CT)

\section{INTRODUCTION}

Headache is a common symptom and a common reason for presentation in emergency department (ED). Patients with headache constitute about $1-4 \%$ of emergency department visits $(1,2)$. Most of the headaches seen in clinical practice are primary headaches, but the possibility of an underlying secondary aetiology requires further diagnostic procedures. Primary headaches include tension-type headache, migraine and trigeminal autonomic cephalalgias. Secondary headaches are classified according to the underlying cause and they can be caused by trauma, vascular disorders, infections, medications, homeostasis disorders, disorders in cerebrospinal fluid flow etc. Main reason for performing a computed tomography (CT) scan is a detection of potentially treatable lesion, such as tumor or vascular malformation. The prevalence of chronic daily headache among adults worldwide is $4 \%$ (3-5). Since the headaches are the reason for often ED visits, performing a CT scan has become extremely frequent. In the past two decades, number of the CT scans performed in the ED has increased by $600 \%$ (6). This increase leads to a higher expo- 
sure to the medical ionising radiation of the population (7), as well as the financial burden for the health system. Studies have found that diagnostic procedures, such as $\mathrm{CT}$ and magnetic resonance (MR), have small contribution in the evaluation of headaches, especially chronic headaches, without neurological abnormalities or history of the previous head trauma (8-11). High pressure is set on a clinician in the ED, from a worried patient, patients family and from legal aspect as well, so the CT scan is often performed without a valid indication (12). The aim of this research is to determine the incidence of the positive CT findings in the ED in patients with headache, without focal neurlogical abnormalities.

\section{MATERIAL AND METHODS}

The results of the native CT scans of the head performed in the emergency department (ED) of the Clinical Hospital Sveti Duh in Zagreb from January 2016 till September 2017 were retrospectively analyzed. Patients were older than 18 and younger than 87, and they presented to the ED because of the headache. We took into the consideration reports made by the selfsame radiologist and patients examined by residents of neurology or neurology specialists. Exclusion criteria were: focal neurological abnormality, previous head trauma, underlying malignancy, brain metastases, previous brain operation, dizzines, fever, nausea, vomiting, coagulopathy. Focal neurological abnormalities include impairments of the nerve, spinal cord or brain that affects a specific region of the body. CT scan reports were divided into three categories: R0 - completely normal finding, R1 - positive finding but clinically insignificant, R3 - positive finding but clinically significant. As clinically significant finding, tumor, hemorrhage and ischemic lesion were taken into the consideration. All of the R2 reports were further evaluated by MR scan and/or CT angiography. Doctors requiring a CT scan were divided into two groups: S0 - resident of neurology, S1 - neurology specialist. For statistical analysis, MedCalc (MedCalc Software, Ostend, Belgium) was used. Results were shown with descriptive statistics. Normality of the distribution of numeric variables was tested with Kolgomor-
ov-Smirnov test. Fisher's exact test was used for comparison of category variables differences. The results were considered statisticaly significant at $p<0.05$. The local ethics committee approved the study.

\section{RESULTS}

After data analysis, 108 patients fulfilled the set criteria, present headache, without focal neurological abnormalities, recent head trauma or other symptoms. Out of 108 patients with median age of $49.5(18-87)$ years old, 68 (63\%) were women with median age of 52 (18-85) years old and 40 (47\%) of them were men with median age of 44.5 (18-87). Classification of the CT scan reports according to its results is shown in Table 1 and according to the doctor requiring a CT scan in Table 2. According to the CT scan reports, there was no statistically significant difference between males and females in all three categories, R0 $(\mathrm{p}=0.819), \mathrm{R} 1 \quad(\mathrm{p}=0.278)$ and $R 2(p=0.286)$. According to the doctor requiring a CT scan, there was no statistically significant difference between residents of neurology and neuology specialists in all theree categories, R0 $(\mathrm{p}=0.651), \mathrm{R} 1(\mathrm{p}=1.00)$ and $\mathrm{R} 2(\mathrm{p}=0.728)$. Positive findings but clinically insignificant are shown in Table 3 and positive findings but clinically significant depending on doctor requiring a $\mathrm{CD}$ scan in Table 4. In five patients diagnosed with tumor, MR showed expansive tumor of the cerebrum in two cases, pituitary tumor in one case, pituitary apoplexy in one case and arteriovenous malformation in one case. In three patients diagnosed with hemorrhage, CT angiography and MR showed subarachnoidal hemorrhage in two cases and one case of arteriovenous malformation bleed. In case of one patient with ischemic lesion finding was confirmed with MR scan. Additional evaluation of nine clinically significant findings showed change of initial diagnosis in two cases, but significance of the finding remained the same.

TABLE 1. CT scan reports according to the results

\begin{tabular}{|l|c|c|c|}
\hline $\begin{array}{l}\text { CT examination } \\
\text { results }\end{array}$ & $\begin{array}{c}\text { Male } \\
\mathbf{N = 4 0}\end{array}$ & $\begin{array}{c}\text { Female } \\
\mathbf{N = 6 8}\end{array}$ & $\begin{array}{c}\text { All patients } \\
\mathbf{N}=\mathbf{1 0 8}\end{array}$ \\
\hline RO & $31 ; 28.7 \%$ & $51 ; 47.2 \%$ & $82 ; 75.9 \%$ \\
\hline R1 & $4 ; 3.7 \%$ & $13 ; 12 \%$ & $17 ; 15.7 \%$ \\
\hline R2 & $5 ; 4.6 \%$ & $4 ; 3.7 \%$ & $9 ; 8.3 \%$ \\
\hline
\end{tabular}


TABLE 2. CT scan reports according to the doctor requiring a CT scan. SO - resident of neurology, S1 - neurology specialist.

\begin{tabular}{|l|c|c|c|c|}
\hline Doctor & R0 & R1 & R2 & All patients \\
\hline S0 & $45 ; 54.9 \%$ & $10 ; 56.5 \%$ & $6 ; 66.7 \%$ & $61 ; 56.5 \%$ \\
\hline S1 & $37 ; 45.1 \%$ & $7 ; 43.5 \%$ & $3 ; 33.3 \%$ & $47 ; 43.5 \%$ \\
\hline
\end{tabular}

TABLE 3. Positive findings but clinically insignificant (R1)

\begin{tabular}{|l|c|}
\hline Diagnosis & N (\%) \\
\hline Microvascular changes and lacunas & $8(47.1 \%)$ \\
\hline Parenhimal calcif ca on & $4(23.5 \%)$ \\
\hline Sinus changes & $4(23.5 \%)$ \\
\hline Asymmetry of the ventricular system & $1(5.9 \%)$ \\
\hline
\end{tabular}

TABLE 4. Positive findings but clinically significant deppending on the doctor requiring a CT scan

\begin{tabular}{|l|c|c|c|}
\hline R2 & $\begin{array}{c}\text { S0 } \\
\text { N = 6 }\end{array}$ & $\begin{array}{c}\text { S1 } \\
\text { N = 3 }\end{array}$ & $\begin{array}{c}\text { All patients R2 } \\
\mathbf{N}=\mathbf{9}(\mathbf{8 . 3 \% )}\end{array}$ \\
\hline tumor & 3 & 2 & $5(3.7 \%)$ \\
\hline hemorrhage & 2 & 1 & $3(3.7 \%)$ \\
\hline ischaemia & 1 & 0 & $1(0.9 \%)$ \\
\hline
\end{tabular}

\section{DISCUSSION}

Headache is a common symptom in medical practice and a common reason for presentation in ED. Diagnostic evaluation of headaches with CT scan remains a controversisal, there are many studies that have confuted the importance of CT scan in headaches without focal neurological abnormalities and without recent head trauma $(8,10,13,14)$. According to some studies diagnostic imaging should only be a consideration when a secondary headache is suspected (15). In certain studies (1622) significant difference was found in the diagnostic imaging reports interpretation between emergency medical doctors, residents of radiology and radiology specialists so we took into the consideration reports made by the selfsame radiologist. Previous studies in diagnostic of clinically significant findings in CT scans of head in patients with headache but without recent head trauma have various results. Jordan et al (8) showed $1.02 \%$ of clinically significant findings, CT imaging was performed with CT scanner of older generation, and the study included patients with fever, all of which had an impact on lowering of incidence of clinically significant findings. Demaerel et al (23) showed 3\%, and Quon et al (24) showed 2.2\% of clinically significant findings. Analysing the incidence of clinically significant findings in this study, screending methods should be taken into the account, considering that all of the patients were examined by res- idents of neurology or neurology specialist unlike in other studies where CT scan was required by emergency medical doctors, general practitioner, internal medicine specialists and other. Ang et al (25) found $8 \%$ clinically significant findings what is similair to our results, while Harris et al (26) found $11 \%$ of abnormal CT scan findings without differentitation between clinically insignificant and significant findings. Bent et al (27) found $10.2 \%$ of clinically significant findings, but patients with focal neurological abnormalities were taken into the account. In this study we found that there is no statistically significant difference between residents of neurology and neurology specialists, according to that we can conclude that competences of residents of neurology and abidance of clinical guidelines provide screening of patients compatible to that of neurology specialists. One of the causes of secondary headache is subarachnoidal hemorrhage (SAH), which is a life-threatening condition. CT scan is a method of choice in diagnosing SAH (28). In this study incidence of SAH is $1.8 \%$, while Morganstern et al (29) published a prospective study with incidence of SAH in patients with headache presenting in ED 4\%, but we should take into the account that the patients with focal neurological abnormalities were excluded in our study. Further evaluation of clinically significant findings with MR scan or CT angiography showed change in diagnosis in two cases, but both of the findings remained clinically significant, that is there was no change in category. Quon et al (24) published a change in category in $4.9 \%$, but in that study mean time of further evaluation was 147 days, with maximum of 584 days, wich leaves a possibility that part of the findings were re-categorized because of the de novo lesions in patients, while in our study all of the patients were further evaluated within the 24 hours of the initial CT scan.

\section{CONCLUSIONS}

Native CT scan is a useful diagnostic tool. In this research was found that $8.3 \%$ of performed CT scans in patients with headache but without focal neurological abnormality or previous head trauma had clinically significant findings. We consider that $8.3 \%$ of clinically significant findings is not negligible, mainly due to the clinical neurological examination preceding the computed tomography. 


\section{REFERENCES}

1. Ramirezlassepas M., Espinosa C.E., Cicero J.J., Johnston K.I., Cipolle R.J., Barber D.I. Predictors of intracranial pathologic findings in patients who seek emergency care because headache. Archives of neurology. 1997; 54(12):1506-9.

2. Torelli P., Campana V., Cervellin G., Manzoni G.C. Management of primary headaches in adult emergency departments: a literature review, the parma ed experience and a therapy flow chart proposal. Neurological sciences. 2010; 31(5):545-53.

3. Scher A.I., Stewart W.F., Liberman J., Lipton R.B. Prevalence of frequent headache in a population sample. Headache. 1998; 38(7):497-506.

4. Lu S.R., Fuh J.I., Chen W.T., Juang K.D., Wang S.J. Chronic daily headache in taipei, taiwan: prevalence, follow-up and outcome predictors. Cephalalgia. 2001; 21(10):980-6.

5. Wang S.J., Fuh J.I., Lu S.R., Liu C.Y., Hsu L.C., Wang P.N. et al. Chronic daily headache in chinese elderly - prevalence, risk factors, and biannual follow-up. Neurology. 2000; 54(2):314-9.

6. Larson D.B., Johnson L.W., Schnell B.M., Salisbury S.R., Forman H.P. National trends in ct use in the emergency department: 1995-2007. Radiology. 2011; 258(1):164-73.

7. Brenner D.J., Hall E.J. Current concepts - computed tomography an increasing source of radiation exposure. New england journal of medicine. 2007; 357(22):2277-84.

8. Jordan Y.J., Lightfoote J.B., Jordan J.E. Computed tomography imaging in the management of headache in the emergency department: cost efficacy and policy implications. Journal of the national medical association. 2009; 101(4):331-5.

9. Kahn C.E., Sanders G.D., Lyons E.A., Kostelic J.K., Macewan D.W., Gordon W.I. Computed-tomography for nontraumatic headache - current utilization and cost-effectiveness. Canadian association of radiologists journal-journal de I association canadienne des radiologistes. 1993; 44(3):189-91.

10. Jordan J.E., Ramirez G.F., Bradley W.G., Chen D.Y., Lightfoote J.B., Song A. Economic and outcomes assessment of magnetic resonance imaging in the evaluation of headache. Journal of the national medical association. 2000; 92(12):573-8.

11. Akpek S., Arac M., Atilla S., Onal B., Yucel C., Isik S. Cost-effectiveness of computed-tomography in the evaluation of patients with headache. Headache. 1995; 35(4):228-30.

12. Stovner L.J., Hagen K., Jensen R., Katsarava Z., Lipton R.B., Scher A.I. et al. The global burden of headache: a documentation of headache prevalence and disability worldwide. Cephalalgia. 2007; 27(3):193-210.

13. Gilbert J.W., Johnson K.M., Larkin G.I., Moore C.I. Atraumatic headache in us emergency departments: recent trends in ct/mri utilisation and factors associated with severe intracranial pathology. Emergency medicine journal. 2012; 29(7):576-81.

14. Sempere A.P., Porta-Etessam J., Medrano V., Garcia-Morales I., Concepcion L., Ramos A. et al. Neuroimaging in the evaluation of patients with non-acute headache. Cephalalgia. 2005; 25(1):30-5.

15. Alter M., Daube J.R., Franklin G., Frishberg B.M., Goldstein M.I., Greenberg M.K. et al. Practice parameter - the utility of neuroima ging in the evaluation of headache in patients with normal neurologic examinations. Neurology. 1994; 44(7):1353-4.

16. Alfaro D., Levitt M.A., English D.K., Williams V., Eisenberg R. Accuracy of interpretation of cranial computed-tomography scans in an emergency-medicine residency program. Annals of emergency medicine. 1995; 25(2):169-74.

17. Snow D.A. Clinical-significance of discrepancies in roentgenographic film interpretation in an acute walk-in area. Journal of general internal medicine. 1986; 1(5):295-9.

18. Gratton M.C., Salomone J.A., Watson W.A. Clinically significant radiograph misinterpretations at an emergency medicine residency program. Annals of emergency medicine. 1990; 19(5):497-502.

19. Kramer M.S., Robertsbrauer R., Williams R.I. Bias and overcall in interpreting chest radiographs in young febrile children. Pediatrics. 1992; 90(1):11-3.

20. Mayhue F.E., Rust D.D., Aldag J.C., Jenkins A.M., Ruthman J.C. Accuracy of interpretations of emergency department radiographs effect of confidence levels. Annals of emergency medicine. 1989; 18(8):826-30.

21. Freed H.A., Shields N.N. Most frequently overlooked radiographically apparent fractures in a teaching hospital emergency department. Annals of emergency medicine. 1984; 13(10):900-4.

22. Fleisher G., Ludwig S., Mcsorley M. Interpretation of pediatric $\mathrm{x}$-ray-films by emergency department pediatricians. Annals of emergency medicine. 1983; 12(3):153-8.

23. Demaerel P., Boelaert I., Wilms G., Baert A.I. The role of cranial computed tomography in the diagnostic work-up of headache. Headache. 1996; 36(6):347-8.

24. Quon J.S., Glikstein R., Lim C.S., Schwarz B.A. Computed tomography for non-traumatic headache in the emergency department and the impact of follow-up testing on altering the initial diagnosis. Emergency radiology. 2015; 22(5):521-5.

25. Ang S.H., Chan Y.C., Mahadevan M. Emergency department headache admissions in an acute care hospital: why do they occur and what can we do about it? Annals academy of medicine singapore. 2009; 38(11):1007-10.

26. Harris B., Hwang U., Lee W.S., Richardson L.D. Disparities in use of computed tomography for patients presenting with headache. American journal of emergency medicine. 2009; 27(3):333-6.

27. Bent C., Lee P.S., Shen P.Y., Bang H.J., Bobinski M. Clinical scoring system may improve yield of head ct of non-trauma emergency department patients. Emergency radiology. 2015; 22(5):511-6.

28. Clinical policy: critical issues in the evaluation and management of patients presenting to the emergency department with acute headache. Annals of emergency medicine. 2002; 39(1):108-22.

29. Morgenstern L.B., Luna-Gonzales H., Huber J.C, Wong S.S., Uthman M.O., Gurian J.H. et al. Worst headache and subarachnoid hemorrhage: prospective, modern computed tomography and spinal fluid analysis. Annals of emergency medicine. 1998; 32(3):297-304.

Conflict of interest: none declared Financial support: none declared 